\title{
KINERJA PENGELOLAAN LIMBAH HOTEL PESERTA PROPER DAN NON PROPER DI KABUPATEN BADUNG, PROVINSI BALI
}

\author{
Putri Nilakandi Perdanawati Pitoyo ${ }^{1 *}$, I Wayan Arthana ${ }^{2)}$, I Made Sudarma ${ }^{3)}$ \\ 1) Badan Lingkungan Hidup Provinsi Bali \\ 2) Fakultas Kelautan dan Perikanan Universitas Udayana \\ 3) Fakultas Pertanian Universitas Udayana \\ *)Email:putri_npp@yahoo.com
}

\begin{abstract}
Bali tourism development can lead to positive and negative impacts that threatening environmental sustainability. This research evaluates the hotel performance of the waste management that includes management of waste water, emission, hazardous, and solid waste by hotel that participate at PROPER and non PROPER. Research using qualitative descriptive method. Not all of non PROPER doing test on waste water quality, chimney emissions quality, an inventory of hazardous waste and solid waste sorting. Wastewater discharge of PROPER hotels ranged from 290.9 to $571.8 \mathrm{~m}^{3} /$ day and non PROPER ranged from 8.4 to 98.1 $\mathrm{m}^{3}$ /day with $\mathrm{NH}_{3}$ parameter values that exceed the quality standards. The quality of chimney emissions were still below the quality standard. The volume of the hazardous waste of PROPER hotels ranged from 66.1 to $181.9 \mathrm{~kg} / \mathrm{month}$ and non PROPER ranged from 5.003 to $103.42 \mathrm{~kg} / \mathrm{month}$. Hazardous waste from the PROPER hotel which has been stored in the TPS hazardous waste. The volume of the solid waste of PROPER hotel ranged from 342.34 to $684.54 \mathrm{~kg} /$ day and non PROPER ranged from 4.83 to $181.51 \mathrm{~kg} / \mathrm{day}$. The PROPER and non PROPER hotel not sort the solid waste. The hotel performance in term of wastewater management, emission, hazardous, and solid waste is better at the PROPER hotel compared to non PROPER participants.
\end{abstract}

Keywords:performance; waste management; PROPER; non PROPER

\section{PENDAHULUAN}

Pembangunan hotel berbintang di Bali mengalami peningkatan dengan rata-rata pertumbuhan sebesar $10,85 \%$ per tahun dari tahun 2011-2013 (BPS, 2013). Keberadaan hotel-hotel tersebut menimbulkan dampak positip dan negatip. Dampak negatip dapat disebabkan oleh limbah hotel yang tidak dikelola dengan baik sehingga dapat mencemari lingkungan. Pengertian limbah menurut Undang-undang Nomor 32 Tahun 2009 adalah sisa suatu usaha dan/atau kegiatan.Limbah erat kaitannya dengan pencemaran, karena limbah inilah yang menjadi substansi pencemaran lingkungan, karena itu, pengolahan limbah sangat dibutuhkan agar tidak mencemari lingkungan (Harmayani, 2007).

Berdasarkan karakteristiknya, limbah dapat digolongkan menjadi empat bagian, yaitu: limbah cair, limbah padat, limbah gas/partikel, dan limbah B3 (Bahan Berbahaya dan Beracun) (Sugiharto, 1987). Air limbah secara umum terdiri dari $99,9 \%$ komponen air dan 0,1\% bahan padatan (Efendi, 2003). Bahan padatan itu sendiri 70\% berupa bahan organik dan 30\% berupa bahan anorganik. Menurut Supriyanto (2000), strategi pengelolaan air limbah dimulai dimana limbah dihasilkan sampai tempat air limbah itu dibuang.

Berdasarkan karakteristiknya, sampah hotel adalah sampah sejenis sampah rumah tangga, yaitu terdiri dari sampah organik (sisa makanan), plastik, kertas, logam, kaca, kayu, karet, kain dan sebagainya.Secara umum, dampak yang ditimbulkan oleh sampah dapat membawa efek langsung dan tidak langsung (Slamet, 1996 dalam Wardi, 2011). Paradigma baru dalam Undang-undang Nomor 18 Tahun 2008 memandang sampah sebagai sumber daya yang mempunyai nilai ekonomi dan dapat dimanfaatkan, misalnya untuk energi kompos, pupuk ataupun bahan baku industri (Wibowo, 2013).

Gas adalah uap yang dihasilkan dari zat padat atau zat cair karena dipanaskan atau menguap sendiri, contohnya: CO2, CO, SOx, NOx.Partikel, adalah suatu bentuk pencemaran udara yang berasal dari zarah $\neg$ zarah kecil yang terdispersi ke udara, baik berupa padatan, cairan, maupun padatan dan cairan secara bersama-sama, contohnya: debu, asap, kabut, dan lain-lain (Fardiaz, 1992).Komponen pencemar udara tersebut di atas bisa mencemari udara secara sendiri-sendiri, atau dapat pula mencemari secara bersama-sama (Sugiarti, 2009).

Yang termasuk limbah B3 antara lain adalah bahan baku yang berbahaya dan beracun yang tidak digunakan lagi karena rusak, sisa kemasan, tumpahan, sisa proses, dan oli bekas yang memerlukan penanganan dan pengolahan khusus.Prinsip-prinsip dasar pengelolaan limbah B3: minimasi limbah, polluter pays principle, pengolahan 
dan penimbunan limbah B3 di dekat sumber, pembangunan berkelanjutan berwawasan lingkungan, dan konsep "cradle to grave" dan "cradle to cradle (Ratman, 2010).

PROPER (Program of Pollution Control Evaluation and Rating) adalah program penilaian terhadap upaya penanggung jawab usaha dan atau kegiatan dalam mengendalikan pencemaran dan atau kerusakan lingkungan hidup (KLH, 2014).PROPER ini dicanangkan oleh Kementerian Lingkungan Hidup yang bertujuan untuk mengevaluasi kinerja perusahaan dalam pengelolaan lingkungan. Data PROPER tahun 2014, hotel bintang lima yang ada di Kabupaten Badung rata-rata menghasilkan air limbah sebesar 364,4 $\mathrm{m}^{3} /$ hari dan limbah B3 (Bahan Berbahaya dan Beracun) sebesar 2,3 kg/hari (BLH Provinsi Bali, 2014).

Kinerja hotel dalam pengelolaan limbah terawasi dan terpantau secara kontinyu oleh pemerintah bagi yang telah mengikuti PROPER. Sampai dengan tahun 2014, jumlah hotel yang telah mengikuti PROPER sebanyak 28 buah, atau 21\% dari total keseluruhan hotel bintang empat dan lima yang ada di Provinsi Bali. Masih banyak hotel yang belum mengikuti PROPER, namun ini tidak berarti bahwa kinerja pengelolaan limbah hotel tersebut tidak baik. Penelitian ini untuk membuktikan bahwa PROPER bukan menjadi alasan utama hotel melakukan pengelolaan lingkungan, karena sudah seharusnya setiap manajemen hotel memiliki komitmen yang kuat dalam pengelolaan lingkungandan menunjukkan tanggung jawab terhadap kelestarian lingkungan dengan melakukan pengelolaan lingkungan dan pemantauan lingkungan (Lensiana, 2010).Oleh karena itu penelitian ini dilakukan untuk mengevaluasi kinerja pengelolaan limbah hotel, baik yang ikut PROPER maupun tidak ikut PROPER.

\section{METODOLOGI}

\subsection{Lokasi dan Waktu Penelitian}

Penelitian ini dilaksanakan di delapan hotel bintang empat dan lima yang ada di Kelurahan Jimbaran, Kecamatan Kuta Selatan, Kabupaten

Tabel 1. Lokasi Penelitian

\begin{tabular}{lll}
\hline No & Nama Hotel & Kategori Bintang \\
\hline & Peserta PROPER & \\
1. & Intercontinental Bali Resort (A) & 5 \\
2. & Four Season Resort Bali at Jimbaran (B) & 5 \\
3. & Ayana Resort \& Spa Bali (C) & 5 \\
& Non PROPER & \\
4. & Kayu Manis Jimbaran Private Estate \& Spa (D) & 5 \\
5. & Le Meridien Bali Jimbaran (E) & 5 \\
6. & Jimbaran Puri Bali (F) & 4 \\
7. & Keraton Jimbaran (G) & 4 \\
8. & Karma Jimbaran (H) & 4 \\
\hline
\end{tabular}

Badung, antara lain dapat dilihat pada Tabel 1. Penelitian dilaksanakan bulan Januari - Juni 2015.

\subsection{Bahan dan Instrumen Penelitian}

Bahan dan instrumen yang dibutuhkan dalam penelitian ini adalah blanko isian data/check list, $\mathrm{pH}$ meter, thermometer, peralatan sampling, dan kamera digital.

\subsection{Prosedur Penelitian}

Prosedurpenelitian yang dilakukan adalah persiapan, pengumpulan data, dan pengambilan data primer di lapangan dengan empat komponen utama penelitian, yaitu:

1). kegiatan pengelolaan air limbah: identifikasi pemakaian air bersih, pengukuran debit air limbah, data kualitas air limbah (outlet), dan data IPAL(kapasitas dan diagram proses IPAL);

2). kegiatan pengelolaan limbah emisi: indentifikasi sumber emisi (jenis, jumlah, dan kapasitas) dan data kualitas emisicerobong (genset dan/atau boiler);

3). kegiatan pengelolaan limbah B3: identifikasi limbah B3 (jenis, jumlah, dan volume), pencatatan limbah B3 (logbook dan neraca), bangunan/gudang penyimpanan limbah B3 (ketentuan teknis pengemasan dan penyimpanan limbah B3), dan rencana tindak lanjut pengelolaan limbah B3 (kerjasama dengan pihak ketiga);

4). kegiatan pengelolaan sampah: identifikasi jenis dan jumlah sampah, kegiatan pemilahan sampah di sumber, dan rencana tindak lanjut pengelolaan sampah (kerjasama dengan pihak ketiga).

\subsection{Analisis Data}

Proses analisis data dilakukan dengan tahapan sebagai berikut:

1. tingkat pengetahuan manajemen hotel dalam pengelolaan limbah melalui analisis deskriptif kualitatif yaitu dari kuisioner yang dibagikan kepada hotel;

2. data yang diperoleh dari pengamatan langsung terhadap kegiatan pengelolaan limbah hotel, disusun dalam bentuk tabel dan dianalisis secara deskriptif;

3. data kualitas air limbah dianalisis di LaboratoriumAnalitik Universitas Udayana;

4. data beban pencemaran (BP) air limbah yang dihasilkan hotel dapat dianalisis dengan mengalikan konsentrasibahan pencemar (C) dengan kapasitas aliran air limbah (Q) yang mengandung bahan pencemar, seperti dinyatakan dalam persamaan berikut:

$$
\mathrm{BP}=\mathrm{C} \times \mathrm{Q}
$$

5. kinerja pengelolaan limbah hotel diperoleh dengan: 
a. melihat sejauh mana pemahaman pengelola hotel terkait regulasi tentang pengelolaan lingkungan melalui kuisioner maupun pengamatan langsung di lapangan. Hal ini bisa dilihat melalui pemenuhan ketentuan teknis dan administrasi yang telah dilakukan hotel dalam pengelolaan limbah;

b. evaluasi kinerja IPAL, dengan melihat proses pengolahan air limbah serta kualitas air limbah yang dihasilkan.

\section{HASIL DAN PEMBAHASAN}

\subsection{Kondisi Hotel}

Kondisi kedelapan hotel dengan melihat luas area, jumlah kamar, tingkat hunian kamar, persentase hunian kamar, pemakaian air bersih, dan jumlah karyawan disajikan pada Tabel 2.

Tabel 2 menunjukkan bahwa penggunaan air bersih tertinggi pada Four Season Resort Bali at Jimbaran. Penggunaan air bersih diperuntukkan untuk kegiatan kamar mandi/toilet, wastafel, dapur/ restaurant, laundry, spa,penyiraman, pengisian air kolam dan lain-lain. Penggunaan air bersih tergantung pada jumlah kamar dan tingkat hunian kamar, jumlah karyawanserta utilitas yang ada. Four Season Resort Bali at Jimbaran memilikijumlah kamar dan jumlah karyawan lebih kecil dari Intercontinental Bali Resort dan Ayana Resort \& Spa Bali, namun penggunaan air bersihnya terbanyak. Hal ini dikarenakan tipe bangunan Four Season Resort Bali at Jimbaran berupa vila dengan kolam renang pribadi, sehingga penggunaan air bersih lebih banyak untuk pengisian air kolam, namun debit air limbah yang dihasilkan kecil.

\subsection{Kinerja Pengelolaan Air Limbah}

Kedelapan hotel memiliki tipe IPAL yang sama yaitu menggunakan proses fisik, biologi dan kimia.Proses aerasi dengan mekanisme difuser aerator, dimana suplai oksigen bearsal dari blower. Yang membedakan adalah ada yang menggunakan tambahan bakteri (EM4) guna membantu proses pengolahan, seperti pada Kayu Manis Jimbaran Private Estate \& Spa, Le Meridien Bali Jimbaran, dan Keraton Jimbaran Resort. Seluruh IPAL tidak ada yang menggunakan tambahan bahan kimia. IPAL yang ada di hotel minimal terdiri dari bak inlet à bak aerasi à bak sedimentasi à bak penampung akhir. Data debit dan kualitas air limbah (efluen) dapat dilihat pada Tabel 3.

Tabel 2. KondisiHotel

\begin{tabular}{|c|c|c|c|c|c|c|c|}
\hline No & Nama Hotel & Luas Area (ha) & Jumlah kamar (buah) & $\begin{array}{c}\text { Rata-rata Tingkat } \\
\text { Hunian Kamar } \\
\text { per Hari }\end{array}$ & $\begin{array}{l}\text { Persentase } \\
\text { Hunian } \\
\text { per Bulan (\%) }\end{array}$ & $\begin{array}{c}\text { Debit Pemakaian } \\
\text { Air Bersih (m³/bulan) }\end{array}$ & $\begin{array}{c}\text { Jumlah Karyawan } \\
\text { (orang) }\end{array}$ \\
\hline & Hotel PROPER & & & & & & \\
\hline 1. & A & 14,0 & 417 & 265 & 63,5 & 23.200 & 846 \\
\hline 2. & B & 13,8 & 147 & 78 & 53,0 & 32.663 & 643 \\
\hline 3. & $\stackrel{\text { C }}{\text { Hotel Non ROPER }}$ & 70,0 & 368 & 308 & 83,7 & 22.650 & 1.233 \\
\hline 4. & D & 3,0 & 19 & 8 & 42,1 & 950 & 105 \\
\hline 5. & $\mathrm{E}$ & 1,5 & 118 & 88 & 74,6 & 3.716 & 153 \\
\hline 6. & $\mathrm{~F}$ & 2,5 & 64 & 34 & 53,1 & 2.796 & 202 \\
\hline 7. & G & 1,5 & 102 & 67 & 65,7 & 12.134 & 145 \\
\hline 8. & $\mathrm{H}$ & 8,0 & 40 & 10 & 25,0 & 5.346 & 127 \\
\hline
\end{tabular}

Tabel 3. Data Debit dan Kualitas Air Limbah

\begin{tabular}{|c|c|c|c|c|c|c|c|c|c|c|}
\hline \multirow{2}{*}{ Nama Hotel } & \multirow{2}{*}{$\begin{array}{c}\text { Kapasitas } \\
\text { IPAL } \\
\left(\mathrm{m}^{3} / \text { hari }\right) \\
\end{array}$} & \multirow{2}{*}{$\begin{array}{l}\text { DebitAir } \\
\text { Limbah } \\
\left(\mathrm{m}^{3} / \text { hari) }\right.\end{array}$} & \multicolumn{8}{|c|}{ Hasil Uji } \\
\hline & & & $\mathrm{TSS}(\mathrm{mg} / \mathrm{L})$ & $\mathrm{pH}$ & $\mathrm{BOD}_{5}(\mathrm{mg} / \mathrm{L})$ & $\mathrm{COD}(\mathrm{mg} / \mathrm{L})$ & $\mathrm{NH}_{3}(\mathrm{mg} / \mathrm{L})$ & $\mathrm{NO}_{3}(\mathrm{mg} / \mathrm{L})$ & $\mathrm{NO}_{2}(\mathrm{mg} / \mathrm{L})$ & $\mathrm{H}_{2} \mathrm{~S}(\mathrm{mg} / \mathrm{L})$ \\
\hline \multicolumn{11}{|l|}{ Hotel PROPER } \\
\hline A & 600 & 407,2 & 7,90 & 6,85 & 1,16 & 2,12 & $0,09^{*}$ & $17,38^{*}$ & 0,004 & $0,042^{*}$ \\
\hline$B$ & 380 & 290,9 & 4,05 & 7,52 & 3,75 & 7,69 & $0,09^{*}$ & $14,23^{*}$ & 0,014 & ttd \\
\hline C & 920 & 571,8 & 10,02 & 7,12 & 3,24 & 7,69 & $0,65^{*}$ & 1,33 & 0,014 & ttd \\
\hline \multicolumn{11}{|c|}{ Hotel Non PROPER } \\
\hline D & 10 & 8,4 & 8,33 & 7,60 & 11,60 & 23,18 & $1,47^{*}$ & 2,17 & 0,004 & $\mathrm{tdd}$ \\
\hline$E$ & 150 & 98,1 & 37,62 & 6,86 & 6,76 & 13,47 & $0,62^{*}$ & 0,66 & $15,501^{*}$ & ttd \\
\hline $\mathrm{F}$ & 30 & 24,9 & 17,50 & 7,17 & 4,15 & 6,64 & $2,97^{*}$ & $14,98^{*}$ & 0,051 & $0,051^{*}$ \\
\hline G & 210 & 45,4 & 20,31 & 7,60 & 7,25 & 12,60 & $7,21^{*}$ & 1,02 & 0,012 & $0,017^{*}$ \\
\hline $\mathrm{H}$ & Tidak tersedia data & 47,6 & 16,88 & 6,88 & 4,38 & 11,35 & $3,51^{*}$ & $15,16^{*}$ & $0,191^{*}$ & $0,034^{*}$ \\
\hline & $\begin{array}{c}\text { Baku Mutu } \\
\text { (Pergub No. 8/ 2007) }\end{array}$ & 50,00 & $6-9$ & 30,00 & 50,00 & 0,02 & 10 & 0,06 & 0,01 & \\
\hline
\end{tabular}

Keterangan:

* : melebihi baku mutu 
Tabel 3 memperlihatkan bahwa seluruh hotel debit air limbah yang diolah masih dibawah kapasitas IPAL nya kecuali Karma Jimbaran karena tidak tersedia data kapasitas IPAL. Bila dibandingkan dengan baku mutu air limbah hotel sesuai dengan Pergub Bali No. 8 tahun 2007, maka untuk kategori hotel PROPER yang terbanyak melewati baku mutu adalah Intercontinental Bali Resort yaitu sebanyak tiga parameter: $\mathrm{NH}_{3}, \mathrm{NO}_{3}$ dan $\mathrm{H}_{2} \mathrm{~S}$. Untuk kategori hotel non PROPER, yang terbanyak melewati baku mutu adalah Karma Jimbaran yaitu sebanyak empat parameter: $\mathrm{NH}_{3}, \mathrm{NO}_{3}, \mathrm{NO}_{2}$ dan $\mathrm{H}_{2} \mathrm{~S}$.

Data beban pencemaran air limbah masingmasing hotel dapat dilihat pada Tabel 4. Beban pencemaran ini dipengaruhi oleh besaran debit dan kualitas air limbah yang dihasilkan. Beban bahan organik (COD, BOD) air limbah yang makin besar menyebabkan penurunan kemampuan degradasi IPAL, sehingga tingkat efisiensi pengolahan mengalami penurunan. Untuk mengantisipasi peningkatan beban bahan organik air limbah di masa yang akan datang, maka perlu dilakukan karakterisasi kondisi operasi dan optimasi proses pengolahan air limbah sehingga diperoleh tingkat efisiensi pengolahan yang tinggi (Fitrahani et al., 2012).

Berdasarkan kondisi IPAL hotel dengan melihat proses pengolahan, kapasitas IPAL dibandingkan dengan debit pengolahan, serta kualitas air limbah yang dihasilkan, maka dapat disusun peringkat IPAL terbaik sebagai berikut:

1. Intercontinental Bali Resort;

2. Ayana Resort \& Spa Bali;

3. Four Season Resort Bali at Jimbaran;

4. Jimbaran Puri Bali;

5. Karma Jimbaran;

6. Le Meridien Bali Jimbaran;

7. Keraton Jimbaran Resort;

8. Kayu Manis Jimbaran Private Estate \& Spa.

Bila melihat parameter kunci indikator kualitas air limbah, yaitu: BOD, COD dan TSS (Santika et al., 1984), maka kualitas air limbah Intercontinental Bali Resort lebih baik dibanding lainnya.Proses pengolahan di IPAL Intercontinental Bali Resortcukup lengkap, terdiri dari pengolahan primer dan sekunder, serta berlangsung proses fisik, biologi dan kimia.Proses aerasi berlangsung selama 24 jam. Proses pengolahan air limbah paling sederhana adalah Kayu Manis Jimbaran Private Estate \& Spa dan Jimbaran Puri Bali, hanya terdiri dari bak inletbak aerasi-bak penampung akhir, tidak terdapat bak pengendapan. Jumlah kompartemen (bak) dan lamanya waktu aerasi berbanding lurus dengan penurunan kadar BOD, COD dan TSS (Anwari dkk, 2011)

Hotel yang belum melaksanakan ketentuan teknis (pemasangan flow meter dan pencatatan debit

Tabel 4. Beban Pencemaran Air Limbah

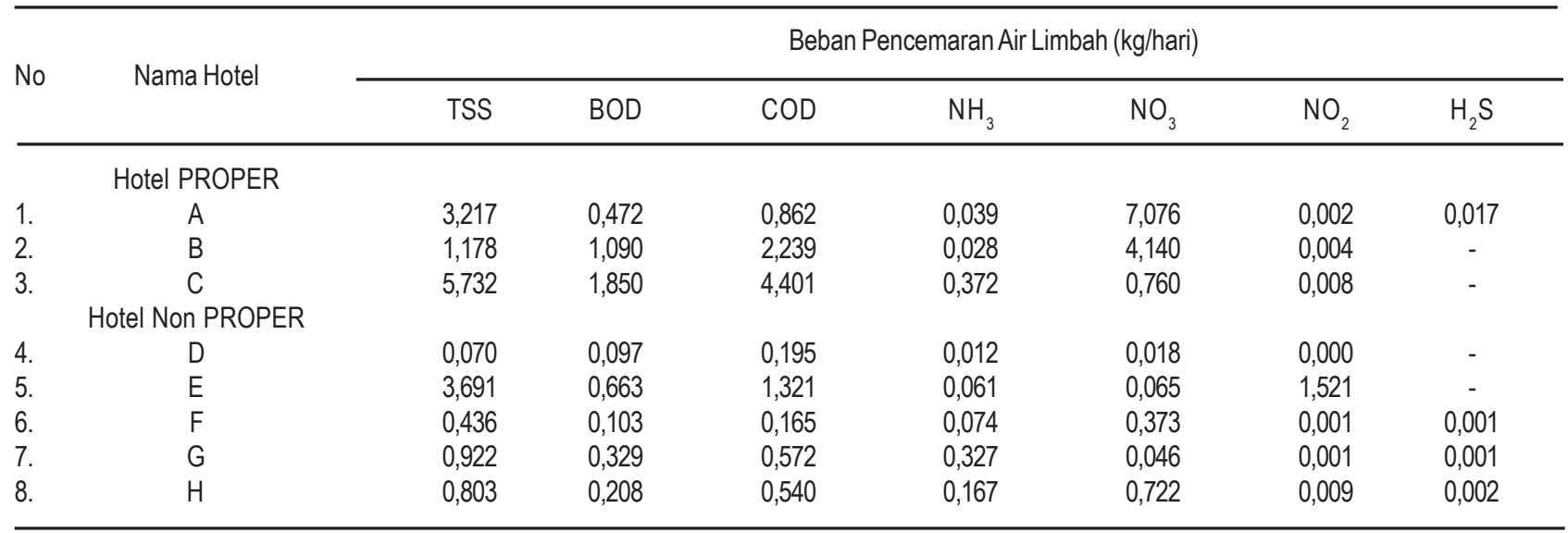

Tabel 5. Kualitas Emisi Cerobong Genset

\begin{tabular}{|c|c|c|c|c|c|}
\hline \multirow{2}{*}{ No } & \multirow{2}{*}{ Kapasitas Genset (KVA) } & \multicolumn{3}{|c|}{ Emisi } & \multirow{2}{*}{ Lokasi } \\
\hline & & $\mathrm{NO}_{2}\left(\mathrm{mg} / \mathrm{m}^{3}\right)$ & $\mathrm{SO}_{2}\left(\mathrm{mg} / \mathrm{m}^{3}\right)$ & Partikel $\left(\mathrm{mg} / \mathrm{m}^{3}\right)$ & \\
\hline 1. & 1.700 & 1,49 & 6,39 & 45,80 & Ayana Resort \& Spa Bali \\
\hline 2. & 1.260 & 4,46 & 6,83 & 52,73 & Ayana Resort \& Spa Bali \\
\hline 3. & 1.250 & 2,74 & 6,63 & 56,96 & Intercontinental Bali Resort \\
\hline 4. & 800 & 0,81 & 5,63 & 132,55 & Four Season Resort Bali at Jimbaran \\
\hline \multirow[t]{2}{*}{5.} & 550 & 9,00 & 25,90 & 58,00 & Keraton Jimbaran Resort \\
\hline & $\begin{array}{c}\text { Baku Mutu } \\
\text { (Pergub No. 8/2007) }\end{array}$ & $1.000,00$ & 800,00 & 350,00 & \\
\hline
\end{tabular}


air limbah harian,pemantauan kualitas air limbah setiap bulan), serta ketentuan administrasi (perizinan dan pelaporan)adalah Kayu Manis Jimbaran, Jimbaran Puri Bali dan Karma Jimbaran. Dilihat dari pemenuhan ketentuan teknis dan administrasi, maka kinerja hotel peserta PROPER lebih baik dibandingkan hotel non PROPER.

\subsection{Kinerja Pengelolaan Limbah Udara}

Sumber emisi tidak bergerak kegiatan hotel berasal dari genset dan boiler. Genset berfungsi sebagai cadangan listrik bila ada pemadaman listrik dari PLN, sehingga pengoperasian genset tidak terjadwal, namun pemanasan (warming up) rutin dilakukan setiap minggu. Boiler berfungsi menghasilkan uap untuk keperluan laundry dan air panas. Kedelapan hotel memiliki genset dan tiga hotel memiliki boiler. Pengujian kualitas emisi cerobong genset baru dilakukan oleh empat hotel dengan hasil pengujian emisi genset dapat dilihat pada Tabel 5 dan hasil pengujian emisi boiler pada Tabel 6 .

Tabel 5 menunjukkan bahwa seluruh emisi cerobong genset hotel dibawah baku mutu yang ditetapkan. Emisi gensettertinggi diberikan oleh Keraton Jimbaran Resort, meskipun kapasitasnya kecil. Tinggi rendahnya emisi genset dipengaruhi oleh waktu operasional, rutinitas pemeliharaan, usia genset, periode penggantian filter oli, serta kualitas bahan bakar.Emisi gas buang pada engine diesel genset dapat diturunkan sebesar 20-24\% dengan menggunakan alat penghemat BBM Electric Fuel Treatment (EFT)dengan beban statis, seperti pada penelitian Hariyadi et al.(2013).

Tabel 6 menunjukkan bahwa seluruh emisi cerobong boiler hotel dibawah baku mutu yang ditetapkan. Emisi boiler tertinggi diberikan oleh Four Season Resort Bali at Jimbaran.Tinggi rendahnya emisi boiler dipengaruhi oleh waktu operasional, rutinitas pemeliharaan, usia boiler, serta kualitas bahan bakar.Untuk skala industri, teknologi pembersihan gas buang $\mathrm{SO}_{2}$ dan $\mathrm{NOx}$ dengan menggunakan teknik iradiasi berkas elektron yang lebih dikenal dengan istilah EBFGT (Electron Beam Flue Gas Treatment) dapat mengurangi kadar polutan gas buang $\mathrm{SO}_{2}$ dan $\mathrm{NOx}$ secara bersamaan sampai batas ambang aman untuk lingkungan (Sudjatmoko, 2008).

Kinerja hotel dalam pengelolaan limbah udara/ emisi, dilihat dari pemenuhan ketentuan teknis (ketersediaan sarana sampling dan pengujian kualitas emisi) dan administrasi (pelaporan), hotel peserta PROPER lebih baik dibandingkan non PROPER.

\subsection{Kinerja Pengelolaan Limbah B3}

Hotel yang belum mengidentifikasi dan mengiventarisasi jenis limbah B3 yang dihasilkan antara lain: Kayu Manis Jimbaran Private Estate \& Spa, Jimbaran Puri Bali, dan Karma Jimbaran. Jenis dan volume limbah B3 masing-masing hotel dapat dilihat pada Tabel 7.Hotel yang menghasilkan limbah B3

Tabel 6. Kualitas Udara Emisi Cerobong Boiler

\begin{tabular}{|c|c|c|c|c|c|}
\hline \multirow{2}{*}{ No } & \multirow{2}{*}{ Kapasitas Boiler (Kg/jam) } & \multicolumn{3}{|c|}{ Emisi } & \multirow{2}{*}{ Lokasi } \\
\hline & & $\mathrm{NO}_{2}\left(\mathrm{mg} / \mathrm{m}^{3}\right)$ & $\mathrm{SO}_{2}\left(\mathrm{mg} / \mathrm{m}^{3}\right)$ & Partikel $\left(\mathrm{mg} / \mathrm{m}^{3}\right)$ & \\
\hline 1. & 6.000 & 1,92 & 11,25 & 22,55 & Intercontinental Bali Resort \\
\hline 2. & 1.600 & 0,11 & 182,10 & 191,40 & Four Season Resort Bali at Jimbaran \\
\hline 3. & 1.500 & 1,83 & 10,18 & 30,30 & Ayana Resort \& Spa Bali \\
\hline \multirow[t]{2}{*}{4.} & 750 & 0,71 & 30,30 & 17,60 & Four Season Resort Bali at Jimbaran \\
\hline & $\begin{array}{c}\text { Baku Mutu } \\
\text { (Pergub No. 8/2007) }\end{array}$ & $1.000,00$ & 800,00 & 350,00 & \\
\hline
\end{tabular}

Tabel 7. Volume Limbah B3

\begin{tabular}{|c|c|c|c|c|c|c|c|c|c|}
\hline \multirow{2}{*}{ No } & \multirow{2}{*}{ Jenis Limbah B3 } & \multicolumn{8}{|c|}{ Volume Limbah B3 (kg/bulan) } \\
\hline & & $A$ & $\mathrm{~B}$ & C & $D$ & $E$ & $\mathrm{~F}$ & G & $\mathrm{H}$ \\
\hline 1. & Batere bekas & 1,800 & 0,500 & 45,500 & 1,200 & 30,000 & 0,300 & 5,900 & 3,000 \\
\hline 2. & Lampu bekas & 49,800 & 13,000 & 33,900 & 0,003 & 20,000 & 16,200 & 8,300 & 10,000 \\
\hline 3. & Aki bekas & - & 25,000 & 57,500 & - & 50,000 & 8,300 & & 4,200 \\
\hline 4. & Oli bekas & 30,000 & 15,000 & 45,000 & 3,800 & 3,000 & 12,000 & 4,500 & 12,000 \\
\hline 5. & Kain majun & - & 1,300 & - & - & - & - & - & - \\
\hline 6. & Filter oli & - & - & - & - & 0,420 & 0,420 & & 0,400 \\
\hline 7. & Cartridge bekas & - & 1,000 & - & - & - & - & - & - \\
\hline 8. & Kemasan bekas B3 & - & 10,300 & - & - & - & - & - & - \\
\hline & Total & 81,600 & 66,100 & 181,900 & 5,003 & 103,420 & 37,220 & 18,700 & 29,600 \\
\hline
\end{tabular}


terbanyak adalah Ayana Resort \& Spa Bali yaitu sebesar 181,9 kg/bulan, dan paling sedikit adalah Kayu Manis Jimbaran Private Estate \& Spa sebesar $5,003 \mathrm{~kg} / \mathrm{bulan}$. Jenis limbah B3 dari kegiatan hotel tidak hanya sebatas yang tercantum pada Tabel 7 , masih ada limbah B3 yang belum teridentifikasi seperti limbah elektronik (remote bekas, PC, dan sebagainya). Bahkan di hotel yang terdapat klinik, wajib mengidentifikasi volume limbah medis yang dihasilkan.

Pengelolaan limbah B3 di hotel sebatas pada penyimpanan sementara sebelum diserahkan kepada pihak ketiga yang berizin. Tempat Penyimpanan Sementara (TPS) limbah B3 tersebut wajib dilengkapi dengan Izin TPS limbah B3 yang diterbitkan oleh Pemerintah Kabupaten/Kota. Kondisi tempat penyimpanan sementara di hotel dapat dilihat pada Tabel 8.
Hotel yang belum memiliki tempat penyimpanan sementara limbah B3 adalah Jimbaran Puri Bali dan Karma Jimbaran. Ada juga hotel yang telah memiliki TPS limbah B3, tetapi masih terdapat sampah non B3 didalam TPS, yaitu Kayu Manis Jimbaran Private Estate \& Spa dan Le Meridien Jimbaran. Hotel yang telah meyerahkan limbah B3nya kepada pihak ketiga adalah Intercontinental Bali Resort, Four Season Resort Bali at Jimbaran, dan Ayana Resort \& Spa Bali.

Pengolahan limbah B3 dimaksudkan untuk dapat sedikit mungkin diminimalisir jika perlu diusahakan sampai nol sehingga tidak membahayakan bagi kehidupan, untuk itu perlu diupayakan pemanfaatan teknologi guna mendukung pelaksanaan pengelolaan limbah B3 dengan sistem 3R (Reduce, Reuse, dan Recycle) (Nugroho, 2013).

Tabel 8. Ketersediaan TPS Limbah B3

\begin{tabular}{|c|c|c|c|c|}
\hline \multirow{2}{*}{ Uraian } & \multicolumn{4}{|c|}{ Nama Hotel } \\
\hline & $A$ & B & C & $D$ \\
\hline $\begin{array}{l}\text { Ketersediaan } \\
\text { TPS LB3 }\end{array}$ & Ada & Ada & Ada & Ada \\
\hline $\begin{array}{l}\text { Kondisi penyimpanan } \\
\text { limbah B3 }\end{array}$ & $\begin{array}{l}\text { Penyimpanan dan penge- } \\
\text { masan limbah B3 sudah } \\
\text { sesuai dengan ketentuan }\end{array}$ & $\begin{array}{l}\text { Penyimpanan dan penge- } \\
\text { masan limbah B3 sudah } \\
\text { sesuai dengan ketentuan }\end{array}$ & $\begin{array}{l}\text { - Kebersihan TPS limbah } \\
\text { B3 kurang terjaga } \\
\text { - Pengemasan limbah B3 } \\
\text { tidak sesuai peraturan } \\
\text { - Penempatan B3 dan } \\
\text { limbah B3 menjadi satu }\end{array}$ & $\begin{array}{l}\text { - Limbah yang disimpan dalam } \\
\text { TPS limbah B3 bercampur } \\
\text { dengan sampah anorganik } \\
\text { - Pengemasan limbah B3 tidak } \\
\text { sesuai peraturan. }\end{array}$ \\
\hline
\end{tabular}

\begin{tabular}{|c|c|c|c|c|}
\hline \multirow[b]{2}{*}{ Uraian } & \multicolumn{4}{|c|}{ Nama Hotel } \\
\hline & $E$ & $\mathrm{~F}$ & G & $\mathrm{H}$ \\
\hline $\begin{array}{l}\text { Ketersediaan } \\
\text { TPS LB3 }\end{array}$ & Ada & Tidak ada & Ada & Tidak ada \\
\hline $\begin{array}{l}\text { Kondisi penyimpanan } \\
\text { limbah B3 }\end{array}$ & $\begin{array}{l}\text { Limbah yang disimpan. } \\
\text { dalam TPS limbah B3 } \\
\text { bercampur dengan sampah } \\
\text { anorganik seperti: kaca, } \\
\text { keramik }\end{array}$ & $\begin{array}{l}\text { - Limbah oli bekas disimpan } \\
\text { dir. genset. } \\
\text { - Limbah B3 bercampur } \\
\text { dengan sampah anorganik }\end{array}$ & $\begin{array}{l}\text { Penyimpanan dan penge- } \\
\text { masan limbah B3 sudah } \\
\text { sesuai dengan ketentuan } \\
\text { yang berlaku }\end{array}$ & $\begin{array}{l}\text { - Limbah oli bekas disimpan } \\
\text { di r. genset. } \\
\text { - Limbah B3 bercampur } \\
\text { dengan sampah anorganik }\end{array}$ \\
\hline
\end{tabular}

Tabel 9. Volume Sampah

\begin{tabular}{|c|c|c|c|c|c|c|c|c|c|}
\hline \multirow{2}{*}{ No } & \multirow{2}{*}{ Jenis Sampah } & \multicolumn{7}{|c|}{ Volume Sampah (kg/hari) } & \multirow[b]{2}{*}{$\mathrm{H}$} \\
\hline & & $A$ & B & C & D & $\mathrm{E}$ & $\mathrm{F}$ & G & \\
\hline 1. & Kertas & 3,18 & 5,62 & 12,52 & 0,33 & 5,05 & - & 2,41 & - \\
\hline 2. & Logam & 0,58 & 4,40 & 4,37 & 0,75 & 1,39 & - & 0,20 & - \\
\hline 3. & Kaca & 1,19 & 1,67 & 7,58 & 1,85 & 1,53 & - & 0,49 & - \\
\hline 4. & Plastik & 1,40 & 8,00 & 6,32 & - & 4,14 & - & 1,04 & - \\
\hline 5. & Lilin & 0,23 & 0,39 & 2,77 & - & 0,12 & - & & - \\
\hline \multirow[t]{2}{*}{6.} & $\begin{array}{l}\text { Organik: } \\
\text { - sampah kebun }\end{array}$ & & & & & & & & \\
\hline & - sampah dapur & 335,76 & 545,67 & 650,98 & 1,90 & 163,26 & 89,08 & 121,41 & - \\
\hline \multirow[t]{2}{*}{7.} & Campuran & - & - & - & - & - & 92,43 & - & 153,53 \\
\hline & Total & 342,34 & 565,75 & 684,54 & 4,83 & 175,49 & 181,51 & 125,55 & 153,53 \\
\hline
\end{tabular}


Kinerja hotel dalam pengelolaan limbah B3, dilihat dari pemenuhan ketentuan teknis (sarana TPS limbah B3) dan administrasi (perizinan dan pelaporan), hotel peserta PROPER lebih baik dibandingkan non PROPER.

\subsection{Kinerja Pengelolaan Sampah}

Sampah yang dihasilkan kegiatan hotel termasuk sampah sejenis sampah rumah tangga yang berasal dari kegiatan komersial dan termasuk kategori sampah domestik. Volume sampah hotel dipengaruhi oleh beberapa faktor, antara lain: fasilitas yang dimiliki, jumlah karyawan, luasan area, serta upaya 3R (Reuse, Reduce dan Recycle) yang telah dilakukan. Volume sampah hotel berdasarkan jenisnya dapat dilihat pada Tabel 9 . Hotel yang menghasilkan sampah terbanyak adalah Ayana Resort \& Spayaitu sebesar 684,54 kg/hari dan paling sedikit adalah Kayu Manis Jimbaran Private Estate \& Spasebesar 4,83 kg/hari. Hotel yang belum mendata volume sampah berdasarkan jenisnya adalah Jimbaran Puri Bali dan Karma Jimbaran.

Didalam pengelolaan sampah, seluruh hotel bekerjasama dengan pihak ketiga yaitu PT. Jimbaran Lestari.Pihak hotel bertanggungjawab untuk mengumpulkan sampah di area hotel dan menampungnya di tempat penampungan sampah. Sampah yang terkumpul belum terpilah, pemilahan sampah dilakukan oleh pihak ketiga.Pemilahan sampah hanya dilakukan di dapur yaitu sampah basah dan sampah kering. Sampah yang dihasilkan oleh kegiatan hotel dapat dioptimalkan dan prospek pengembangannya yaitu daur ulang untuk sampah jenis plastik dan kertas, serta composting untuk sampah jenis sisa makanan dan sisa halaman (Sofyan, 2014).

Kinerja hotel dalam pengelolaan limbah padat (sampah), dilihat dari kegiatan pemilahan sampah, hotel peserta PROPER dan non PROPER sama-sama belum melakukan kegiatan tersebut. Dilihat dari administrasi (pelaporan), hotel peserta PROPER lebih baik daripada non PROPER, karena sudah melaporkan secara rutin kepada instansi terkait. Hotel non PROPER yang sudah melaporkan kegiatan pengelolaan sampah secara rutin kepada instansi terkait adalah Le Meridien Jimbaran dan Keraton Jimbaran.

\section{SIMPULAN DAN SARAN}

\subsection{Simpulan}

1. Debit air limbah hotel yang PROPER berkisar 290,9 - 571,8 $\mathrm{m}^{3} /$ hari dan non PROPER berkisar $8,4-98,1 \mathrm{~m}^{3}$ /hari. Volume limbah B3 hotel yang PROPER berkisar 66,1-181,9 kg/bulan dan non PROPER berkisar 5,003 - 103,42 kg/
bulan.Volume sampah hotel yang PROPER berkisar $342,34-684,54 \mathrm{~kg} / \mathrm{hari}$ dan non PROPER berkisar 4,83-181,51 kg/hari.

2. Kualitas air limbah parameter $\mathrm{NH}_{3}$ seluruh hotel melebihi baku mutu. Kualitas udara emisi seluruh hotel masih berada di bawah nilai ambang batas.

3. Hotel peserta PROPER menunjukkan kinerja yang lebih baik dibandingkan dengan hotel non PROPER dalam pengelolaan limbah cair, udara, B3 dan sampah.

4. Kerja IPAL hotel peserta PROPER lebih baik dibandingkan dengan hotel non PROPER.

5. Pengelola hotel non PROPER belum sepenuhnya mampu melakukan kewajiban dalam memantau dan mengelola limbah hotel.

\subsection{Saran}

1. Hotel non PROPER agar meningkatkan kinerja pengelolaan limbahnya khususnya untuk hotel: Kayu Manis Jimbaran, Jimbaran Puri Bali, dan Karma Jimbaran. Disarankan hoel yang bersangkutan melakukan kegiatan pengendalian pencemaran air yang meliputi: menguji kualitas air limbah setiap bulan dan mengajukan permohonan Izin Pembuangan Limbah Cair (IPLC); kegiatan pengendalian pencemaran udara yang meliputi: menyediakan sarana dan prasarana sampling emisi dan menguji kualitas emisi cerobong; kegiatan pengelolaan limbah B3 yang meliputi: mendata jenis dan volume limbah B3 yang dihasilkan, menyediakan bangunan TPS limbah B3, dan mengajukan izin TPS limbah B3; serta kegiatan pengelolaan sampah yang meliputi menginventarisasi jumlah dan jenis sampah yang dihasilkan.

2. Menyediakan tempat sampah terpilah dan melaksanakan metode 3R (Reuse, Reduce dan Recycle) bagi seluruh hotel. Dengan kondisi sampah yang sudah terpilah antara sampah organik dan anorganik akan dapat meningkatkan nilai ekonomi sampah tersebut.

\section{DAFTAR PUSTAKA}

Anwari, F., Muslim, G.R., Hadi, A., dan Mirwan, A. 2011. Studi Penurunan Kadar BOD, COD, TSS dan $\mathrm{pH}$ Limbah Pabrik Tahu Menggunakan Metode Aerasi Bertingkat. Jurnal Prestasi, Vol: 1, No: 1.

Badan Lingkungan Hidup Provinsi Bali. 2014. Laporan Pelaksanaan PROPER 2013-2014 di Provinsi Bali. Denpasar.

Badan Pusat Statistik Provinsi Bali. 2013. Bali dalam Angka Tahun 2013. Denpasar. 
Effendi, H. 2003.Telaah Kualitas Air Bagi Pengelolaan Sumber Daya dan Lingkungan Perairan. Yogyakarta: PT. Kanisius.

Fitrahani, L.Z., Indrasti, N.S., dan Suprihatin. 2012. Karakterisasi Kondisi Operasi dan Optimasi Proses Pengolahan Air Limbah Industri Pangan. Jurnal Agroindustri Indonesia. Vol: 1, No: 2.

Hariyadi, S., Fakhrurroja, H., dan Tanu, E. 2012. Analisis Hasil Uji Terap Alat Penghemat BBM Electric Fuel Treatment Pada Engine Diesel Genset 35 KVA dengan Beban Statis. UPT. Bandung: Balai Pengembangan Instrumentasi LIPI.

Harmayani, K.D. dan Konsukartha, I.G.M. 2007. Pencemaran Air Tanah Akibat Pembuangan Limbah Domestik di Lingkungan Kumuh. Studi Kasus Banjar Ubung Sari, Kelurahan Ubung. Jurnal Permukiman Natah, Vol: 5, No: 2.

Kementerian Lingkungan Hidup Republik Indonesia. 2014. Peraturan Menteri Lingkungan Hidup Nomor 3 Tahun 2014 tentang Program Penilaian Peringkat Kinerja Perusahaan dalam Pengelolaan Lingkungan Hidup. Jakarta.

Lensiana. 2010. "Partisipasi Hotel dalam Pengelolaan Lingkungan di Kecamatan Gianyar (Studi Kasus Terhadap Sistem Pengelolaan Limbah Hotel)" (tesis). Denpasar: Universitas Udayana.

Nugroho, S.S. 2013. Pengelolaan Limbah Bahan Berbahaya dan Beracun Perspektif Undangundang Nomor 32 Tahun 2009 tentang Perlindungan dan Pengelolaan Lingkungan Hidup. Jurnal Sosial. Vol: 14, No: 2.

Ratman, C.S. dan Syafrudin. 2010. Penerapan Pengelolaan Limbah B3 di PT. Toyota Motor Manufacturing Indonesia. Jurnal PRESIPITASI, Vol: 7, No: 2.
Sofyan, L. 2015. "Studi Pengelolaan Sampah Hotel dan Prospek Pengembangannya di Kota Makassar (Studi Kasus Hotel Grand Clarion, Hotel Sahid Jaya dan Hotel Imperial Aryaduta di Kota Makassar)" (skripsi). Makassar: Universitas Hasanuddin.

Sudjatmoko. 2008. Analisis Aspek Teknis dan Ekonomis Pengolahan Gas Buang dengan Berkas Elektron. Jurnal GANENDRA. Vol: 11, No: 2.

Sugiarti. 2009. Gas Pencemar Udara dan Pengaruhnya Bagi Kesehatan Manusia. Jurnal Chemica, Vol: 10, No: 1.

Sugiharto. 1987. Dasar-Dasar Pengelolaan Air Limbah. Cetakan Pertama. Jakarta: UI Press.

Supriyanto, B. 2000. Pengelolaan Air Limbah yang Berwawasan Lingkungan Suatu Strategi dan Langkah Penanganannya. Jurnal Teknologi Lingkungan, Vol: 1, No: 1.

Undang-undang Republik Indonesia Nomor 32 Tahun 2009 tentang Perlindungan dan Pengelolaan Lingkungan Hidup.

Undang-undang Republik Indonesia Nomor 18 Tahun 2008 tentang Pengelolaan Sampah.

Wardi, I.N. 2011. Pengelolaan Sampah Berbasis Sosial Budaya: Upaya Mengatasi Masalah Lingkungan di Bali. Jurnal Bumi Lestari, Vol: 11, No: 1.

Wibowo, M. dan Andreani, F. 2013. Analisis Penerapan Sistem Manajemen Limbah Berdasarkan Sertifikasi Eco-Hotel di Sheraton Surabaya Hotel and Towers. Jurnal Hospitality dan Manajemen Jasa, Vol: 2, No: 1. 